\title{
Las metáforas urbanas en el Plan Maestro del Centro Histórico de la capital hondureña
}

\author{
Daniela Navarrete Cálix
}

Artículo

Afiliación: Escuela Agrícola Panamericana Zamorano, Honduras.

E-mail: navarrete.daniela76@gmail.com

Recibido: 9 de diciembre del 2019

Aceptado: 29 de abril del 2020

\section{Daniela Navarreto Cálix}

Doctora en Estudios Urbanos (Escuela de Altos Estudios en Ciencias Sociales, París), Maestra en Territorios Espacios Sociedades (EHESS), en Geografía, ordenamiento y urbanismo (Sorbonne Nouvelle), en Historia del Arte (Universidad Paul Valéry) y Licenciada en Historia (Universidad Nacional Autónoma de Honduras). Investigadora en grupo de trabajo CLACSO Buenos Aires. Ha publicado tres libros y varios artículos en revistas de diversos países. Profesora asociada de la Escuela Agrícola Panamericana Zamorano, Honduras.

\begin{abstract}
Resumen
En este artículo comentaremos el uso de metáforas urbanas a lo largo del Plan Maestro del Centro Histórico del Distrito Central, capital de Honduras. Esta reflexión tiene su génesis en las Jornadas de Estudios Urbanos convocados por la Universidad de Costa Rica, en junio del 2019. Víctor Delgadillo demostró en su conferencia la politización y ausencia de neutralidad en tales adjetivaciones urbanas contemporáneas, verdaderos instrumentos en la aplicación de lógicas globales en Latinoamérica'. De acuerdo con el autor, estas metáforas, abundantes y de carácter optimista, en realidad actúan como estrategias a fuerte dosis publicitaria para promover la aceptación de discursos que acarrean la promoción de productos (como las ciudades inteligentes y el uso de tecnología urbana). Entonces, a la vez que ocultan sus objetivos económicos, no toman en cuenta las realidades y verdaderas necesidades de las ciudades que buscan redimir. ¿Cómo se instrumentalizaron los urbanismos planetarios por medio de metáforas urbanas en la capital de Honduras? ¿Quiénes los promueven? Efectivamente, estas estrategias se han ido aplicando en particular a partir de la elaboración del Plan Maestro para el Centro Histórico del Distrito Central. Con base en los análisis de Delgadillo y otros autores, resulta fundamental relevar el efecto persuasivo dado a este conjunto de vocablos, verdadero lenguaje político al servicio de legitimación de estos proyectos, espejismos de participación ciudadana y supuesto consenso. La propuesta en cuestión fue elaborada por la Universidad de Sevilla y la Agencia de Cooperación Española para el Desarrollo en el año 2018. ¿Lograron estas metáforas persuadir a los capitalinos de la idoneidad del Plan Maestro?
\end{abstract}

Palabras clave: dominación cultural; España; Honduras; urbanismo marxista global.

\section{The Urban Metaphors in the Master Plan of the Historic Centre of the Honduran Capital}

\section{Abstract:}

This article will discuss the use of urban metaphors throughout the Master Plan of the Historic Center of the Central District, the capital of Honduras. This reflection has its genesis in the Urban Studies Conference convened by the University of Costa Rica, in June 2019. Víctor Delgadillo demonstrated in his conference the politicization and absence of neutrality in such contemporary urban adjectives, true instruments in the application of global logic in Latin America. According to the author, these abundant and optimistic metaphors act as high-dose advertising strategies to promote the acceptance of speeches, which lead to the promotion of products (such as smart cities and the use of urban technology). So, at the same time that they hide their economic objectives, they do not take into account the realities and true needs of the cities that seek to redeem. How were planetary urbanisms instrumentalized by means of urban metaphors in the capital of Honduras? Who promotes them? Indeed, these strategies have been applied from the elaboration of the Master Plan for the Historic Center of the Central District. Based on the analyzes of Delgadillo and other authors, it is essential to reveal the persuasive effect given to this set of words, true political language at the service of legitimizing these projects, mirages of citizen participation and supposed consensus. The proposal in question was developed by the University of Seville and the Spanish Development Cooperation Agency in 2018. Did these metaphors succeed in persuading the capital of the suitability of the Master Plan?

Keywords: cultural domination; Spain; Honduras; global marxist urbanism. 


\section{Introducción: urbanización planetaria en el Centro Histórico del Distrito Central}

omo en muchas ciudades del mundo en vías de desarrollo, las ideas y conceptos urbanos que se han aplicado a la capital hondureña son los generados en buena medida por tecnócratas y académicos extranjeros. Esta asimetría se logra gracias al poder económico en que se sustentan, que se vuelve también cultural e intelectual (Bourdieu y Wacquant, 2001). Esto no es nada nuevo en Honduras, desde la llegada de las Ordenanzas de fundación y poblamiento de Felipe II en 1578, hasta la creación de la primera Planificación Metropolitana, Metroplan, en 1978 (Navarrete, 2018). Durante los 400 años que discurrieron entre esos dos momentos, hubo evidentemente múltiples políticas públicas, algunas emanadas también por técnicos locales. Dos de entre ellas destacan como las más radicales, por el cambio de sentido que imprimieron en la ciudad simbólica y material. La primera fue en el siglo XIX, cuando la Reforma liberal traslada la capital nacional a Tegucigalpa en 1880, por lo que se introducen cambios urbanos encaminados a materializar ideales liberales, racionalistas, laicistas e higienistas. Con ello se establecieron las bases para romper con el sentido ideológico, arquitectónico, social y económico de la ciudad hispánica. Fue un proceso largo que se consolidó en 1938 con la unión de las dos alcaldías, la de Comayagüela, antiguo pueblo de indios y el antiguo Real de Minas de Tegucigalpa con el nombre de Distrito Central (Navarrete, 2008). En los años 70 del siglo XX, la planificación urbana Metroplan implantó el modelo económico anglosajón de ciudad, con zonificaciones que fragilizaron el tejido urbano y social compacto, pronunciando la ruptura simbólica llevada a cabo por los liberales respecto a la ciudad barroca compacta en lo urbano, municipal en lo político y religiosa en lo ideológico. Lo anterior se había llevado a cabo con políticas liberales decimonónicas de densificación de los propios y ejidos, ensanchando los límites de la ciudad y re-significando los espacios públicos (bautizos republicanos de las plazas católicas a parques seculares). Con las políticas neoliberales, se abandonan los símbolos urbanos políticos públicos, como los parques, monumentos, avenidas, para dejar a la empresa privada erigir los símbolos urbanos modernos de glorificación del consumo. El crecimiento urbano desde el último cuarto del siglo XX es uno extensivo, individualista y carente de símbolos urbanos político-comunales. De ahí la decadencia paulatina del centro, llamado desde entonces histórico.

En general, los modelos recientes de planificaciones urbanas como los planes maestros responden al objetivo de reconvertir sectores degradados, con una diversidad de apelativos como: renewal, esquemas directores, revitalización, etc. Esas reconversiones obedecen a un ideal de ciudad, deseada o proyectada cuyas dinámicas son las que se buscan integrar y controlar. Para ello se vale de varios actores y aspectos: normativos, legales, jurisdiccionales, económicos, ambiéntales, de diseño, gestión y últimamente, se evocan con énfasis la participación y la ética social y ambiental, al menos en teoría. Este artículo tiene por objetivo identificar en el Plan Maestro del Centro Histórico (PMCH) elaborado con financiamiento de la cooperación española, el uso de un discurso positivo, altruista y ajeno como estrategia de legitimación de ideales que presentan prácticas como las del llamado urbanismo táctico, como las mejores soluciones para la capital de Honduras. Para ello, primero haremos una lectura "historizante" para visualizar las intervenciones recientes. El uso de las metáforas, como dice Delgadillo, es el mecanismo para entender estas intervenciones; recoge en su referido artículo más de 30 adjetivos y metáforas sobre la ciudad. El autor llama nuestra atención sobre el hecho que esta multitud de apelativos en muchos casos denominan los mismos fenómenos 0 debilitan la profundidad de la discusión. Además, nos pone en guardia sobre el origen y la intencionalidad política que recubre a los mismos, que además recogen un pensamiento sobre las ciudades y las utopías urbanas construido por diversos autores y actores desde una perspectiva marxista. Estos lenguajes son una tendencia en los organismos internacionales, y su uso es sine quo non para la aprobación de financiamientos que imparten su dogma de beneficencia incuestionable. Es el caso de la llamada Nueva agenda urbana y los objetivos presentados por la Agenda Urbana de Quito Hábitat III 2016, incluye el eslogan "Una ciudad para todos", que no es el derecho a la ciudad. En un primer momento, y tras contextualizar teóricamente estas metáforas, el artículo revisa tres paradigmas en la gestión de centros históricos: las intervenciones 
de las instituciones públicas y las agencias de cooperación internacional a finales del siglo XX; los antecedentes en la gestión del Centro Histórico del Distrito Central y el génesis del Plan Maestro para el Centro Histórico del Distrito Central 2018 (PMCH). En un segundo momento, contrastamos la realidad frente al ideal que la metáfora se plantea representar. Metodológicamente, esas metáforas y los usos persuasivos de una retórica afectiva son la herramienta que utilizamos para entender la intervención urbana propuesta por el PMCH 2018. Para ello comentaremos lo que al respecto han tratado especialistas como Delgadillo y Musset. En una sección final, expondremos los vocablos usados como estrategia de persuasión en la etapa de validación del $\mathrm{PMCH}$, empleando, como persuasivo, el supuesto hecho de la inclusión y participación ciudadana en la elaboración de este.

\section{Breve historia de la gestión de los centros históricos en Honduras}

\section{Las instituciones públicas y las agencias de cooperación internacional}

Desde el año 1996, el Instituto de Antropología e Historia (IHAH), las Alcaldías Municipales (Gobiernos locales) y la Cooperación Internacional (la Agencia Española para la Cooperación Internacional y el Desarrollo, la Agencia Sueca de Desarrollo Internacional y el Programa de Naciones Unidas para el Desarrollo) han trabajado conjuntamente en proyectos de puesta en valor y gestión del patrimonio cultural de Honduras, cuyos resultados obtenidos han tenido gran relevancia a nivel local, nacional e incluso fuera de Honduras. En el tema de centros históricos, por su conexión con el patrimonio colonial, la agencia de cooperación internacional con mayor incidencia ha sido la española (AECID).

Entre sus primeras actuaciones en Honduras, destaca en la década de los 90 el proyecto de restauración del centro histórico de Comayagua, Comayagua Colonial (AECID, 2016). Comayagua fue la antigua capital provincial española, actualmente es una ciudad intermedia, situada en el centro del país y bien comunicada por las mejores vías terrestres, dos puertos marítimos y próximamente un aeropuerto internacional. El resultado material del proyecto de restauración permitió arrancar otras iniciativas, notablemente las de inversión turística que ha generado un realce económico, sobre todo alrededor de actividades estacionales ligadas al turismo religioso (Semana Santa, Ferias Patronales, etc.).

El Programa Comayagua Colonial, iniciado en 1996, fue un proyecto piloto que surgió con el objetivo de desarrollar metodologías de rescate y conservación del centro histórico de Comayagua, fortaleciendo en alguna medida la alianza entre el Instituto Hondureño de Antropología e Historia, IHAH y el gobierno municipal. Se lograron como resultados globales la restauración arquitectónica del centro histórico, elaboración de instrumentos técnicos (Plan Particular, Reglamento) y de una instancia técnica institucional (Oficina del Centro Histórico integrada por representantes del IHAH y de la Alcaldía).

Sin embargo, y desde el inicio del proyecto, no se abordó la apropiación nacionallocal del mismo, ya que depende en su totalidad del financiamiento español. En parte esto obedece a la incipiente existencia en Honduras, de gremios profesionales en torno a la conservación y gestión del patrimonio cultural (arquitectos, historiadores, restauradores, etc.). De manera que los interlocutores locales no se posicionan frente a los cooperantes, ni en lo económico ni en lo académico. Esto ha creado una subordinación que se traduce en una dicotomía entre los actores: por un lado, la Oficina del Centro Histórico $(\mathrm{OCH})$ de las instituciones públicas (IHAH-AMC), limitada a expedir permisos de construcción y por otro el Programa Comayagua Colonial (o PCC, financiado por la $\mathrm{AECl}$ ) autor de obras faraónicas en la ciudad. Sólo para ilustrar, la $\mathrm{OCH}$ cuenta con dos arquitectos y un presupuesto que no cubre siquiera los gastos operativos de la oficina; en tanto el PCC en su momento dispuso de más de 40 asalariados desde Gerencia, arquitectos, secretarias y conductores y una Escuela Taller de artesanos. Esto generó por parte de las autoridades locales, una postura de complacencia hacia el PCC y de indiferencia hacia la OCH. Además, la gestión del PCC no tuvo presencia de otro actor: la ciudadanía. Comayagua ha contado desde sus inicios urbanos con 
numerosas organizaciones, alrededor de cofradías religiosas y círculos culturales que revelan forma de participación y organización ciudadana.

Además de Comayagua, la AECID continuó su posicionamiento en el patrimonio urbano en Honduras, así como en Latinoamérica, con la restauración de Centros Históricos, con proyectos en Gracias, mancomunidad de Colosuca (ambos en el departamento de Lempira), Ojojona (en Francisco Morazán) y Amapala (en Valle). Un dato curioso es que los proyectos denominados "Plan Maestro" no dejan ningún instrumento o planificación urbana, sino que son acciones de restauración puntual en espacios públicos, entre otras (AECID, 2016).

La revitalización del Centro Histórico de Santa Rosa de Copán es una experiencia disímil a las mencionadas gracias al equilibrio de actuaciones entre diferentes actores, tanto nacionales (IHAH, Alcaldía, Universidad), cooperantes (como el PNUD/ASDI), como de la población civil organizada. Efectivamente, Santa Rosa de Copán es un caso modélico por contar con una Agencia para el Desarrollo Local (ADELSAR) y otro cúmulo de organizaciones por sectores, como la Comisión Ciudadana para el centro histórico, lo que apropia a los habitantes y garantiza no sólo la sostenibilidad de las inversiones en el tiempo, sino también de una cultura ciudadana participativa. Esto se logró combinando las políticas, los trabajos de infraestructura y las acciones de revitalización del centro histórico a través de restauraciones comunales, cabildos abiertos y mecanismos artístico-culturales. Comparado con la experiencia en Comayagua, aunque Santa Rosa es un proyecto asumido totalmente por las autoridades hondureñas (IHAH-Alcaldía) y auto sostenible.

En el 2006 se firmó la VI Comisión Mixta de Cooperación entre los Gobiernos de España y Honduras, para impulsar entre otros, el Programa Patrimonio para el Desarrollo de la $\mathrm{AECl}$ (hoy AECID). Este marco de cooperación dio lugar al "Proyecto Nacional de Fortalecimiento Institucional para la Gestión del Patrimonio Cultural: Ios centros históricos", IHAH-AECID. En este se consideró fundamental la participación de otros actores vinculados con la gestión del patrimonio cultural, como los representantes municipales, las instituciones públicas y culturales, y la ciudadanía en general. Gracias a los fondos españoles se impulsó la investigación sobre centros históricos hondureños, investigaciones de calidad elaboradas por historiadores nacionales. Entre estas publicaciones, dos fueron sobre Tegucigalpa (una guía histórica-turística y dos investigaciones histórica-urbanas ${ }^{2}$ ).

En los últimos años, sin embargo, las experiencias exitosas en centros históricos a nivel nacional e internacional y las tendencias de cooperación financiera para erradicar la pobreza a través del turismo (esto es una estrategia clara para el Banco Interamericano de Desarrollo, el Banco Mundial y las Agencias de Cooperación) han despertado el interés de las autoridades por la gestión del Patrimonio como medio para acceder a fuentes de financiamiento y mostrarse al día ante las corrientes de desarrollo actuales.

\section{Antecedentes locales en la gestión del Centro Histórico del Distrito Central}

A nivel nacional y a pesar de las diversas experiencias, el IHAH a la fecha, no cuenta con una metodología o estrategia clara para abordar la implementación de un plan de revitalización y gestión de centros históricos en Honduras. En nuestro contexto nacional las autoridades centrales, locales y la población en general no se identifican de manera consciente con sus centros urbanos y tampoco visualizan la importancia cultural, social y económica de la conservación del patrimonio cultural como un recurso para el desarrollo sostenible y con equidad de nuestras comunidades.

2 Colección Centros Históricos, Instituto Hondureño de Antropología e Historia 2008-2012.
En el caso específico del Distrito Central, la Alcaldía Municipal del Distrito Central (AMDC) ya había emprendido actuaciones encaminadas para recuperar al Centro Histórico de su decadencia. En el 2006, la administración de Ricardo Álvarez (20062012) empezó por el restablecimiento del Paseo Liquidámbar, la primera calle con uso peatonal que se creó en 1978 e invadida en los años 90 por el comercio informal. De ahí surgió la creación de la Gerencia del Centro Histórico de la AMDC, a cargo de manejar esta porción de la ciudad desde un punto de vista técnico-urbano. También se designó para el cuidado y manejo de zonas de interés especial. Esta unidad actúa 
en coordinación con el Instituto Hondureño de Antropología e Historia (IHAH), con quien suscribió un convenio en el mes de septiembre de 2007, con el fin de generar un proceso de revitalización de las condiciones físicas, paisajísticas, económicas y urbanas de la zona y así lograr el mejoramiento de la calidad de vida de los habitantes de la misma. Se hace un especial énfasis en la revitalización del patrimonio edificado, los espacios públicos y trama urbana, así como en la integración de la comunidad en estas acciones, para crear conciencia de nuestro patrimonio cultural como bien (AMDC, 2019). En la práctica se limitó a coordinación de instituciones para la renovación del Inventario de Bienes Inmuebles Patrimoniales del Distrito Central. Una experiencia interesante, aunque descontinuada, fue el desarrollo del Taller SIRCHAL con patrocinio de la AMDC, Embajada de Francia y la participación de Instituciones públicas, culturales y sociedad civil en agosto de 2008. El Sitio de revitalización de Centros Históricos de América Latina tiene su sede en París y es dirigidos por un arquitecto chileno, Leo Orellana, con el apoyo de la UNESCO. Como resultado directo del SIRCHAL, varias instituciones públicas y privadas implicadas en la gestión de esta porción urbana, conformaron en 2008 la Comisión Ciudadana para el Centro Histórico. En la práctica es una mesa interinstitucional integrada por académicos y profesionales hondureños en áreas de las Ciencias Sociales, Arquitectura y Gestión cultural, que busca llamar la atención a las múltiples problemáticas que van desde la impericia técnica de los responsables públicos, intervenciones fuera de regla de los propietarios, usos indebidos o cualquier otra amenaza hacia el patrimonio cultural. Esto incluyó hacer contrapeso a las decisiones de la AMDC.

\section{El génesis del Plan Maestro para el Centro Histórico del Distrito Central 2018}

En el 2011 la AECID realizó uno de los primeros acercamientos al centro histórico del Distrito Central. Su autor fue un equipo liderado por el arquitecto español Javier Ramos Guallart, urbanista, tecnócrata de trayectoria en su país (León Noticias, 24/4/2017). Según el informe de Ramos, fue la AECID quien contrató sus servicios profesionales para: 1) dar a conocer su experiencia en el caso de Santiago de Compostela, 2) hacer el diagnóstico de la situación del CHDC, 3) identificar las capacidades técnicas de la AMDC para su gestión, y 4) las necesidades que puede cubrir la Cooperación Española3. El trabajo de este urbanista fue realizado de manera unilateral y sin incluir técnicos y profesionales hondureños, ni sus investigaciones, práctica instalada de antemano en la cooperación española. Por ejemplo, Ramos impartió en Tegucigalpa conferencias sobre revitalización de centros históricos y a pesar de existir una experiencia reciente con SIRCHAL, así como otras fortalezas ${ }^{4}$, se ignoró por completo a los equipos técnicos y ciudadanos con especialidades en las áreas concernidas. Con esta visión excluyente de las lecturas propias que los hondureños puedan tener sobre su ciudad, se maquilló una "participación" con funcionarios públicos, la gran mayoría con habilidades en política vernácula 0 en burocracia, pero no en temas urbanos o sociales. Así se partió para preparar una propuesta, el Plan Maestro para el Centro Histórico (PMCH), documento que será nuestra principal fuente de análisis y objeto de este artículo.

Con la firma del convenio de cooperación en 2016 entre la Alcaldía Municipal del Distrito Central (AMDC) y la fundación de investigación de la Universidad de Sevilla (US), se dejó claro que estos últimos estarían a cargo de la fabricación del Plan Maestro del Centro Histórico de Tegucigalpa. Como invitados al proceso que afectaba su propia ciudad, quedaron la AMDC y otros actores, como la Universidad Nacional, el Instituto de Antropología e Historia, el Colegio de Arquitectos y algunas ONG no representativas vinculadas a rubros de gestión cultural, discapacitado y otros. Además de la US, la ONG española Ítaca ambiente elegido, pesquisaron la información disponible en numerosas oficinas públicas, recabando informaciones y datos. Este primer paso, que dejó una rica experiencia de aprendizaje para los estudiantes y docentes españoles, muestra las prácticas que se imponen desde el poder económico de quien brinda la cooperación. La elaboración del Plan Maestro se hizo en conjunto con la Universidad de Sevilla en el marco del proyecto "Fomentar Entornos Urbanos en Convivencia, Seguridad, y con Prevención de Violencia en el Centro Histórico de Tegucigalpa" ejecutado por la AMDC con una inversión de $€ 500.000$ por parte de la Agencia Española de Cooperación 
Internacional para el Desarrollo (AECID, PMCH, cap. 1, p. 5), y en esta lógica son los técnicos españoles (US, Ítaca), los que reportan la mayoría de las contrataciones para el proyecto. Los actores locales han sido identificados, pero su aporte se limita a validar en talleres y reuniones, las disposiciones ya prefiguradas en gabinetes extranjeros.

El documento del Plan Maestro consta de 344 páginas y está organizado en tres ejes estratégicos: Patrimonio, medio ambiente y medio físico, y medio urbano. Dentro de cada eje se incluyen temas que van desde el mejoramiento de la movilidad urbana hasta temas sociales y de seguridad. También comprende tres escalas de trabajo que abarcan desde escala ciudad hasta escala detalle en la que cada ciudadano puede contribuir al desarrollo del Centro Histórico (AECID, 2019).

Haremos una observación más cercana a la cuarta parte, dedicada a la socialización, diagnóstico participativo e implicación de la ciudadanía. Esto en razón que la participación ciudadana es la metáfora que valida o legitima las acciones previamente definidas sin ningún consenso ciudadano.

En primera, es la definición del Paisaje Urbano Histórico (PUH) como objeto de la intervención, concepto usado también por la UNESCO. La US argumenta en el PMCH sobre los atributos del círculo virtuoso entre el patrimonio natural y el edificado. La simbiosis de éstos en los espacios públicos desataría emociones de autoestima positivas que generarían valores sociales y culturales como el respeto y la pertenencia ( $\mathrm{PMCH}$, cap. 2, p. 13). También se legitima la propuesta por estar alineada con los objetivos de la Agenda 21 Local, derivada de la Cumbre de Río o Cumbre de la Tierra. Grosso modo se trata de darle seguimiento a las macro metas en el espacio de gobiernos locales y su entorno, bajo el argumento de responsabilidad compartida y colaboración.

Para redondear los objetivos, en las conclusiones se insiste en "el paisaje como instrumento de potenciación y defensa de diversidad social y ambiental" (PMCH, cap. 3 , p. 11). Es el paisaje, continúan, el que "nos lleva a tratar las relaciones ecológicas, económicas, afectivas y emotivas en un territorio" (p. 11). Cabe aclarar que el uso de la palabra diversidad se refirió en el sentido de lo social (mujeres, niños, discapacitados) pero no de la diversidad de opiniones sobre la elaboración del PM. La inclusión se obtuvo con cuotas de estos grupos con todo su derecho, pero por su proporción sin representatividad del conjunto y, ante todo, su inclusión es resaltada en el logo del proyecto.

\section{El uso de la metáfora como estrategia de persuasión de políticas y proyectos}

Como bien lo manifestaba Lefebvre, es importante recordar que los ideales urbanos se generan desde los centros y se expanden a las periferias más allá de fronteras nacionales (Lefebvre, 1970). A esta idea es a lo que Brenner (2013) llama urbanización planetaria. Mattos agrega que estas tendencias comunes a escala planetaria, es un fenómeno que acompaña la universalización del capitalismo y tiene carácter mundial (Delgadillo, 2016), citando a Lefevbre en su último trabajo (1989), "La ciudad que se diluye en la metamorfosis planetaria". Es de esta manera que se generan las metáforas urbanas y su irradiación hacia otras naciones.

En esta urbanización planetaria, los organismos internacionales y de financiamiento juegan un rol primordial pues son los voceros del capital global y que ejercen su influencia sobre los países a través de políticas condicionadas a ayudas económicas. Delgadillo nos recuerda que la imposición teórica en materia de planificación urbana en América Latina tiene varias vías. Una de ellas son los círculos académicos o laborales que los adoptan libremente; y otras es cuando son impuestas por profesores universitarios y a través de políticas urbanas públicas. Este es precisamente lo que tuvo lugar en este caso de estudio, pues derivó de la alianza entre la Universidad de Sevilla, con su cuerpo de catedráticos y estudiantes, con los fondos de la cooperación española. Juntos crean el Plan Maestro para el Centro Histórico del Distrito Central, constituyendo un ejemplo más de imposición de urbanismo planetario, a través de la elaboración del Plan Maestro para el Centro Histórico del Distrito Central. 
Para entender mejor la diversidad de metáforas, Delgadillo las clasifica según la fuente que las emana y los objetivos que busca. Así tenemos dos grupos principales: Por un lado, las que replican los académicos y entidades internacionales en la búsqueda de la competitividad económica particularmente en ciudades que se desindustrializaron y "servicializaron" su base económica, como es el caso de Tegucigalpa. En este grupo encontramos conceptos como ciudades creativas, ciudades inteligentes, entre otras. Por su parte, los organismos internacionales comenzaron a fomentar algunas estrategias urbanas para que las ciudades confrontaran las desventajas de los procesos de globalización económica y desastres derivados del cambio climático bajo conceptos como ciudades resilientes. Asimismo, diversos académicos abiertamente denuncian los efectos sociales perversos del capitalismo neoliberal globalizado y hablan de ciudades neoliberales, despojos, gentrificación, etc.

Por su abundancia e historia, podría decirse que las metáforas médicas son un subgénero aparte, como bien lo diseca Galvis (2019). Lerner (2014), por ejemplo, en su obra Urban Acupuncture, sugiere que el "colesterol urbano, la acumulación en nuestras venas y arterias del uso excesivo del automóvil" es producto de la zonificación y la circulación vehicular. Una vez hiperbolizado el hecho urbano mediante la metáfora médica patológica, se completa con la cura. En este caso, el autor señala las reflexiones de Casanova y Hernández (2011) que proponen la regeneración de la vida pública mediante acupuntura del espacio público. Este llamado también urbanismo táctico, consiste en una serie de pequeñas intervenciones que regeneran el espacio público urbano. Una parte importante de esta práctica es la incorporación participativa de las comunidades. Según sus autores, se generaría un efecto de contagio positivo sobre la ciudad en general. Este urbanismo táctico es una de las metodologías puestas en marcha en el $\mathrm{PMCH}$, con modalidades participativas incluidas y que veremos más adelante. Las críticas a este tipo de intervención, continua Galvis (2019), son profusas y coinciden en cuestionar que conducen a la gentrificación (por mencionar algunos, Peck, 2005; Crouch, 1998; Shatkin, 2011).

Existen sobrados ejemplos en la región Latinoamericana sobre las intenciones de las metáforas urbanas como estrategias de persuasión en las planificaciones urbanas planetarias. Tal es el caso de la ciudad de Puebla, México. En el estudio de caso presentado por Valverde y Álvarez (ICA, 2018) se demostró como en la renovación urbana ahí ha estado puesto al servicio del turismo, que no es sinónimo de la población. Se implementó un Plan que en realidad se limitó a inventariar, el Estado se retiró de la inversión y las renovaciones puntuales que se hicieron fueron para hotelería y comercios. No se atendieron las causas de las rupturas (la desigualdad social) sino que se dieron soluciones puntuales que resultaron en parches urbanos. En esa misma sintonía, Dos Santos (ICA, 2018) revela en Belo Horizonte las mismas estrategias empresariales aplicadas a lo urbano, a saber: ciudades emprendedoras, planeamiento estratégico, inversiones público-privadas, obras de modernización, incentivo al turismo, internacionalización, marketing urbano y más. Todas estas estrategias revelan una "transposición de prácticas y herramientas de administración empresarial para la gestión urbana, cuyo origen viene de la crisis de los 70, la globalización, el neoliberalismo y competitividad urbana" (Dos Santos, 2018).

La metodología de trabajo del PMCH se fundamenta en la metáfora de la ciudad afectiva (Bisquert, 1997) y basadas a su vez en la fórmula del "afecto como antídoto del miedo" de Mike Davis (1995), citado en el documento (PMCH, cap. 5, p. 43). Para los autores, la premisa es que en el CHDC hay que recuperar "un afecto y un sentimiento de pertenencia". Ello permitiría la regeneración de un sentimiento de comunidad a través de los vínculos de afecto y confianza, esta generación del afecto a través de la percepción es, para los autores del PM, el canal que permite llegar a la ciudad afectiva. Es imprescindible definir cómo entienden los autores el afecto entre población, territorio y habitantes. Para ellos, este vínculo se alcanzaría a través de la comunicación y marketing (PMCH, cap. 5, p. 43), con eventos promocionales, tecnológicos y de nuevas artesanías. Es decir, un afecto basado en la publicidad y el consumismo.

Además de adjetivos del orden de lo emotivo como el afecto, la pertenencia y la comunidad, identifican al espacio físico de convivencia como el resumen de utilidad y belleza para que proliferen o se reinventen estos sentimientos de identidad a través 
del patrimonio natural, cultural e inmaterial. Cabe destacar que este sentido de ciudad se conoce desde la Edad Media en Europa y fue traído de España a América a partir del siglo XVI. En la lógica del urbanismo planetario pues, se busca justificar los viejos beneficios de la ciudad a partir de los nuevos utilitarismos. Estos fueron expuestos cuando se celebró en el 2014 el Foro Mundial Urbano en Medellín. Al respecto, voces críticas se alzaron para denunciar "el gran supermercado de la pobreza urbana dedicado, principalmente a dar buena conciencia a sus organizadores principales y participantes, casi todos convencidos de pensar y actuar por el bien de los grupos menos favorecidos (eufemismo usado en lugar de clases sociales dominadas)" (Musset, 2015). Por inverosímil que parezca, el PMCH señala como referentes políticos e ideológicos a los movimientos más extremos de expropiación de ciudad: desde el Occupied Wall Street, al 15-M de Madrid y hasta las primaveras árabes. Pero estos manifiestos idealistas y militantes se estrellan con las prácticas, como la falta de transparencia en cuanto a los competitivos salarios de los consultores, en el contexto de realidades paupérrimas. Un concepto coloquial francés resume la contradicción en que incurren los voceros del urbanismo planetario. Conocidos como bobó (viene de la unión de las primeras sílabas de burgués 'bourge' y bohemio 'bohème'). Estos burgueses alternativos 0 hípsters se ven a sí mismos como pivotes entre la vanguardia radical y salvadora de los desposeídos, a la vez que su éxito profesional se explica por el rol que juegan en la diseminación de las lógicas globales.

También las reflexiones de Ríos Llamas nos ayudan a comprender estos no dichos, pues en las últimas décadas el afán de "afirmar creencias y legitimar ideas" con palabras bien escogidas para atraer turismo e inversiones han sido el pilar para anunciar los atributos del esplendor y progreso urbano global (2016). Esta es la ironía del discurso urbano global: se han tomado los conceptos y vocabularios de los críticos al urbanismo global y se han resignificado estas ideas para convertirlas en productos inofensivos, pero que rinden grandes dividendos en el plano simbólico y financiero (Musset, 2015). Así se han organizado en Tegucigalpa desde el 2018 este tipo de eventos en que se fusionan publicidades innovadoras, con una identidad popular en un contexto patrimonial. Los llamados Festivales Naranjas, en realidad son mercados navideños, pero sin las tradiciones características, revestido de aire más exclusivo con venta de productos haute-gamme para un público de ingresos medios-altos, en el centro de la ciudad para pasarlos por eventos populares, aunque los precios no lo sean, pues el objetivo es fomentar los sectores ligados a la innovación y la economía creativa (Fig. 1).

Figura 1. La metáfora "creativa": los Festivales Naranjas en el centro histórico.

Fuente: Diario La Tribuna, 21 de noviembre 2019 https://www.latribuna.hn/2019/11/21/hoy-arranca-elfestival-naranja-en-tegucigalpa/

\section{La 'Tribuna \\ * I NOTILIAS $\sim$ HONDURAS $\sim$ SOCIALES $\backsim$ COLUMNAS $\backsim$ OPINIONES $\backsim$ SECCIONES $\backsim$ SERVICIOS $~$ VIDEOS VERSIÓN IMPRESA a}

\section{Hoy arranca el Festival Naranja en Tegucigalpa}

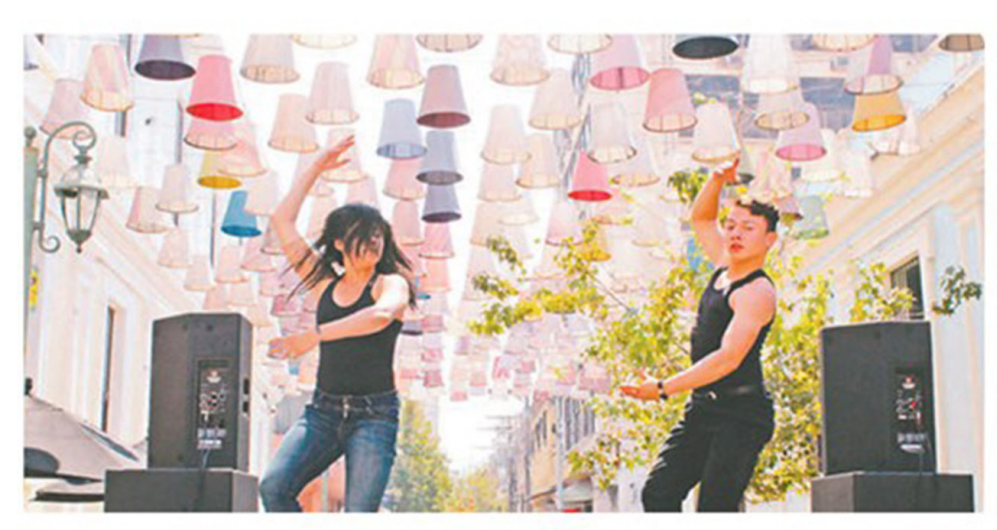

68194
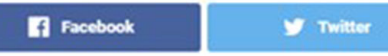

(1) matsapp

Pasarelas de moda a cargo de diseñadores hondureños, muestras de pintura, música, danza de fuego, Edición Invierno 2019", patrocinado por este rotativo.

Creatividad, arte y cultura es la materia prima de la festividad que se propone que actores, diseñadores, joyeros, teatristas, chefs, entre otros, conquisten el mercado en aras de fortalecer la economia.

El evento fue inaugurado el 12 de noviembre con un coctel en la Villa San Miguel del casco histórico de 
En otras palabras, se prescinde de elemento técnicos y científicos inherentes al análisis e intervenciones urbanas, en su lugar se erigen estas adjetivaciones en una especie de culto urbano: con sus dogmas (las ciudades emergentes, afectivas, de amor, sustentables, etc.), su lugar de culto (el centro histórico), su doctrina (Agenda 2030, ODS), su clero (los consultores externos, las agencias internacionales de desarrollo) y su rebaño, es decir los ciudadanos obedientes y acríticos, guiados buenamente en la liturgia de la nueva fe.

\section{El Plan Maestro del Centro Histórico y las lógicas globales}

Delgadillo hace un recuento de los móviles, no siempre transparentes, que las diferentes agendas de desarrollo imponen en países con debilidades intelectuales crónicas, como es el caso de Honduras. En la introducción de uno de los documentos del plan maestro del centro histórico de Tegucigalpa se hace referencia a este fenómeno planetario, desde una perspectiva marxista, o al menos en los vocablos utilizados (mundo globalizado, lógica del mercado neoliberal, poblaciones sometidas al sistema, entre otras). Además de ellos, se hace mención desde la primera página de las amenazas recurrentes de los "países en desarrollo", a saber: su crecimiento demográfico, migración campo-ciudad, inequidad, agresiones a la naturaleza, principales males que escapan a la planificación e inclusión (PMCH cap. 2, p. 5-6). La invocación al miedo, como lo hacían los milenaristas, encarnado en las previsiones de las Naciones Unidas, se resume en el supuesto problema del aumento poblacional y su sostenibilidad (Naciones Unidas, 2017, p. 3). Sólo que, en Honduras, la población es de un poco más de 8 millones de habitantes en una extensión territorial de 192,442 km2, es decir una densidad de 71 habitantes por kilómetro cuadrado, nada apocalíptico. Ante la proclamada incapacidad de los países pobres para desarrollarse, el gobierno global de las Naciones Unidas elaboró en el 2015 la Agenda 2030, misma que se ha ido impartiendo a través de la institución misma y/o de sus subsidiarias. En el caso de Honduras, parte de esa asignación fue dada al gobierno de España, cuya Agencia de cooperación tiene alrededor de 20 años de actuaciones en la gestión del Patrimonio cultural para el desarrollo.

¿Es totalmente inválida una propuesta elaborada por extranjeros con altas competencias profesionales en la materia? No debería serlo, si lo que se busca es lo que se expresa en el discurso oficial, es decir, mejorar las condiciones actuales y sentar las bases para la ayuda sostenible. Pero al no existir mecanismos para potenciar a quienes quedarán al frente de la propuesta, lo que se crea es dependencia económica, técnica e intelectual. Los discursos, nos recuerda Delgadillo, no son neutros ni apolíticos, tienen intenciones y buscan legitimar formas de inversión. Ya expusimos los procedimientos nebulosos en la asignación de consultores externos y locales. Esta ocultación de procedimientos permite todo tipo de inferencias, como la ocultación de objetivos reales. Estos mismos autores proclaman el proyecto como "multidisciplinario, internacional, intergeneracional y abierto" (PMCH, cap. 3, p. 5). En cuanto a sus objetivos, el más importante se declara como "la generación, recuperación y conservación del afecto entre población y territorio, entre habitantes, así como una ciudad amable y justa". Todos estos adjetivos llaman a mover las emotividades más que las causas estructurales de esa ciudad injusta y violenta. Hablar de afectos antes de empleo, servicios básicos, suministro de agua, paz y otras serias carencias en infraestructura que padecen los capitalinos, es reducir una realidad a la obtención de una imagen publicitaria, mediante una metáfora publicitaria de marca, eslogan o selfie point.

Una de las críticas más fuertes a las metáforas emotivas son las que conciernen a la de ciudad justa, metáfora recurrente en el PMCH. En su libro Justice as fairness, John Rawls (2008) inscribe este término en el ámbito de lo experimentado y de la emoción. Musset, por ejemplo, parte desde el hecho histórico de que la ciudad nunca ha sido justa, y tal noción ha sido "un mito retórico al servicio de la visión consensual y neoliberal de los grupos sociales que lo manejan e instrumentan..." (p. 127), de igual forma, continua, "las desigualdades socio-territoriales no son una invención de la ciudad moderna o posmoderna" (2015, p. 127). La cereza sobre el pastel es que los proyectos "emblemáticos" propuestos, supuestamente innovadores, son los que se han venido proponiendo desde hace una década más o menos, desde que Medellín 
fuese presentada como el referente latinoamericano de tal "justicia urbana". "En efecto, no se trata de vender gadgets y aparatos de moda como teleféricos urbanos [...], sino también de reciclar ideas que fueron revolucionarias en su tiempo pero que han sido adaptadas por la doxa neoliberal..." (Musset, 2015, p. 126). Más adelante veremos la materialización de estas frases de Musset, cuando el PMCH propone los mismos gadgets (con teleférico incluido).

\section{La fabricación del consenso}

En cuanto a la validación del proyecto, se recurrió a la metáfora de la participación ciudadana, que llega a nivel de eufemismo, pues fue extremadamente reducida (menos de 500 participaciones), con voz superficial en esta elaboración, por lo que la apropiación es un reto poco plausible, como detallaremos más adelante. Otro aspecto fue que se incorporó al equipo de trabajo a una empresa local de consultoría, ConSur, recién formada con el personal directivo de la Gerencia del Centro Histórico de la AMDC. Ello, según sus directivos, para "generar proyectos arquitectónicos y de renovación urbana que tengan identidad [...], queremos una arquitectura [...] que sea consciente con el ambiente" (Suárez, 2017).

Haciendo uso de las metáforas urbanas del campo de la medicina (Galvis, 2020), cuya abundancia en adjetivaciones urbanas podría decirse son ya un género literario aparte, podríamos decir que ConSur es el placebo de participación técnica local en el PMCH. A la experiencia en el tema por parte de sus propietarios, no siempre airosa, se suma el procedimiento de asignación directa y sin concurso lo que no garantiza una gestión ética y transparente.

En cuanto a los mecanismos de participación utilizados, en repetidas ocasiones se hace énfasis en la propuesta de PM sobre la metodología de los talleres implementados, definidos como un "proceso integral, participativo y sinérgico" (PMCH, 2018, cap. 4, p. 16). Estos conceptos, además de que no se explicaron por ninguna parte, contrasta con las escasas participaciones, que oscilaron en talleres desde 15 personas, hasta un máximo de "medio centenar", o sea, 50. Los autores señalaron que realizaron "escuchas activas de las opiniones de todos los participantes", pero con la escasa afluencia de personas y reducidísima diversidad de sectores que tuvieron, más bien fueron escuchas selectivas.

Los talleres se dirigieron a recoger la percepción ciudadana, de menos de 500 personas, a través de los sentidos (usaron cartografías afectivas, por ejemplo). Con estos métodos cualitativos y no representativos, se validaron los diagnósticos que fundamentan las problemáticas del CHDC: crecimiento desmedido, falta de identidad, destrucción de recursos naturales, históricos y culturales, caos, desorden, desapego y miedo (PMCH cap. 3, p. 7). La población con la que se trabajó en los talleres fue deliberadamente de grupos poco representados y vulnerables, como discapacitados, mujeres, niños y ancianos (PMCH cap. 3, p. 7). Esto discrepa de la metodología de talleres presentada por el PM, definidos como un "proceso integral, participativo y sinérgico". Cumplir con estos vocablos, implicaba fases deliberativas con amplia participación de abajo hacia arriba, con cabildos abiertos, propuestas ciudadanas, plebiscitos ratificatorios con voto obligatorio por la trascendencia y decisiones vinculantes. No ocurrieron. Musset nos advierte sobre el peligro en la utilización de palabras hoy apropiadas por el marco teórico ideológico urbano global: equidad, resiliencia, durabilidad, participación, inclusión e innovación, nociones que no corresponden a ningún concepto científico, por lo menos en las ciencias sociales (2015).

Desde el primer acercamiento de Ramos Guallart en el 2011, y en total coherencia con las prácticas de la AECID en Honduras; las decisiones y políticas del proyecto de PM no son ni participativas ni incluyentes, sino verticales y emanadas por sus financistas. Con ello se favorecía, por un lado, a sus consultores, proveedores españoles y socios locales. Por otro lado, se introdujeron visiones políticas arropadas en discursos buenistas y manipulando con un lenguaje positivo, pero sin ningún espacio a la discusión mucho menos consenso. Para ello, encubrieron sus verdaderas intenciones con metáforas emotivas que presentan como inéditas los viejos ideales de la ciudad occidental. Por 
Figura 2. La metáfora "Hágalo Usted mismo". Fuente: Tomado del Facebook de Plan Maestro Centro Histórico. https://es-la.facebook.com/ PlanMaestrodelCentroHistorico/?ref=page_internal ejemplo, en el lanzamiento del primer Festival Naranja en Comayagüela en 2018, la técnica española invitada, tuvo una participación en la que repitió, casi 10 veces cada una, las palabras inclusión, innovación y creatividad (EL Heraldo, 2018, 17 de noviembre). Como si se tratase del descubrimiento del Tianguis, el Zoco o la Plaza Mayor.

Otras formas de divulgación utilizadas son las redes sociales. En la página de Facebook del PMCH, con 749 me gusta, se comparten fotos de las actividades, afiches publicitarios y titulares de eventos. Entre los comentarios de los usuarios, resaltan los que claman sobre la urgencia de emprender, antes que nada, obras de restauración general en el centro. Estas no son el propósito del PMCH, que proclama su metodología en el urbanismo táctico, otra metáfora sobre inversiones mínimas. Para ello se valen también de estrategias disuasivas estilo "hágalo usted mismo", como consta en esta respuesta en la referida red social:

\begin{tabular}{l} 
AAnabel Alvarez Bustillo, Daniel $\quad \begin{array}{l}\text { Más relevantes } \\
\text { Navas, Victor Rodriguez y } 4 \text { personas más les gusta esto. }\end{array}$ \\
\hline 2 veces compartido \\
\hline
\end{tabular}

Marlen Bahaia Es increíble el estado de la calle que sube de Quinchon Leon hacia la peatonal. Da mucha pena.

Esperamos hagan algo

2 años

$\hookrightarrow$ Ver una respuesta más

(2.) Autor

Plan Maestro del Centro Histórico También te invitamos a que nos acompañes en nuestros próximos talleres, estarán muy interesantes y queremos escuchar las opiniones de todos. Contamos con la participación de la población ya que el cambio comienza por nosotros.

2 años

\section{Eva Moran Ok por aqui estaremos}

\section{Resultados}

Los resultados que tendrá la implementación del $\mathrm{PMCH}$ son aún inciertos. Su presentación se ha hecho publica en círculos cerrados, como presentación oficial ante autoridades municipales y de la cooperación española en 2018 (Fig. 3).

En septiembre de 2019, se hizo una socialización del PM en la Universidad Nacional de Honduras, ante un reducido número de estudiantes y profesores. El panel se integró por los consultores españoles y funcionarios de las instituciones contraparte, la Alcaldía Municipal y el Instituto de Antropología e Historia. En su presentación, uno de los consultores hondureños, con larga trayectoria al servicio de la AECID, se refirió al blindaje indiscutible que porta la propuesta y proyecto de PM, dado "al liderazgo confiable para ejecutar este proyecto sin los políticos (locales), sino con nosotros". Los funcionarios locales presentes en el salón no refutaron la aseveración, lo que denota que las metáforas no sólo han cumplido su objetivo de legitimar los discursos de urbanismo planetario en detrimento de los actores locales, sino que estos están completamente alienados y conformes con tal discurso. Habría que preguntarse si la estrategia de ciudad afectiva que fortalece la autoestima de los ciudadanos no podría incluir también la de sus técnicos municipales y patrimoniales. 
Figura 3. Presentación pública del PMCH, 8 de $>$ marzo 2018.

Fuente: http://www.aecid.hn/sitio/index.php/ noticias/385-planmaestro-tegucigalpa

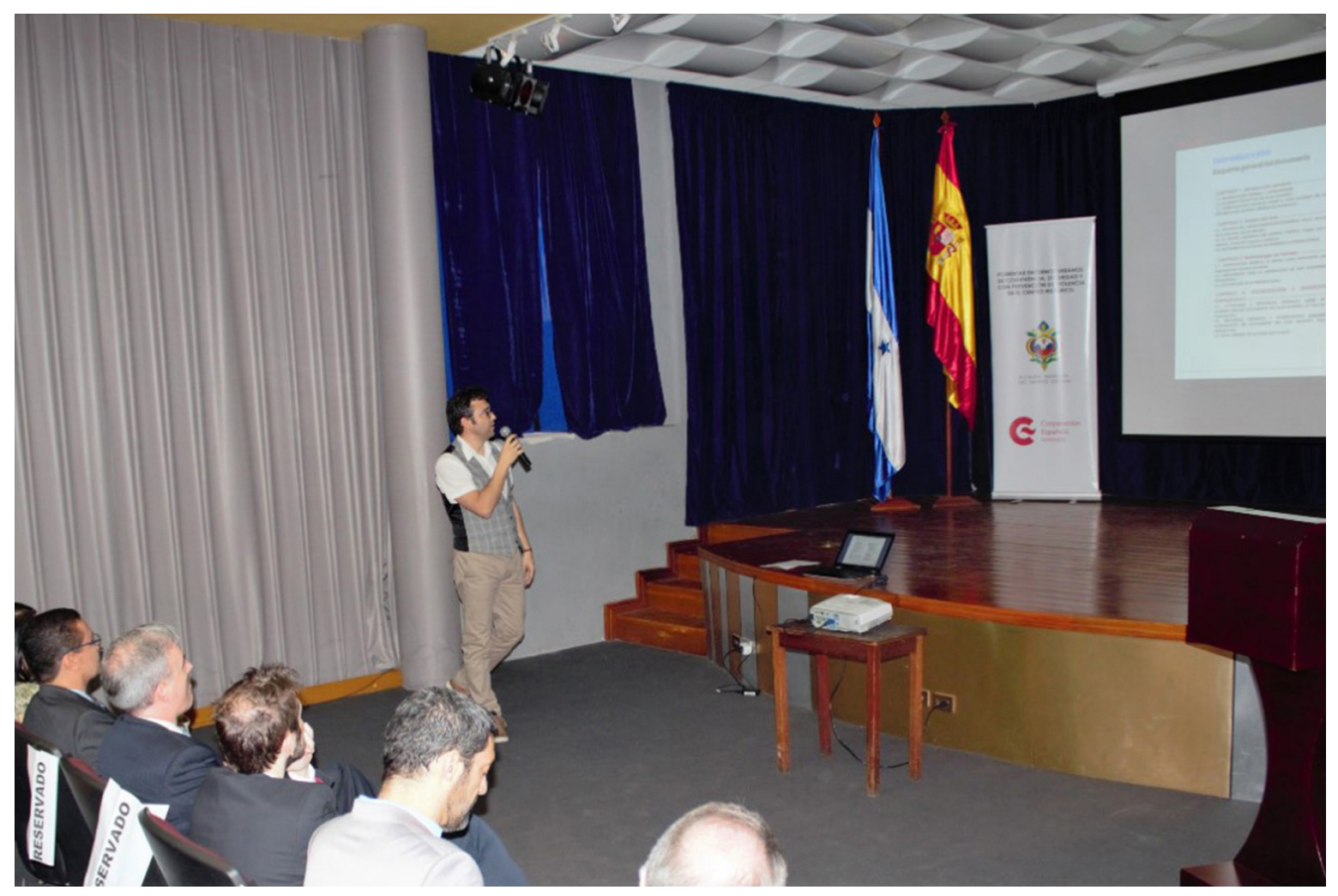

Luego, los talleres integrales, participativos y sinérgicos no incluyeron a la población clave del centro histórico, como los vendedores ambulantes, muchos de ellos niños, ancianos y mujeres. Por último, la exigua cantidad de participantes de los talleres y la clara imposición de la ideología y percepciones de un grupo de consultores no permite la posibilidad de un resultado participativo, local ni sostenible en el tiempo.

Las bases ideológicas que motivaron el documento denominado Plan Maestro para el Centro Histórico del Distrito Central son de claros tintes marxistas, posturas vistas con desconfianza por la conservadora sociedad hondureña. Donde deberíamos encontrar una herramienta técnica y rigurosa, encontramos una con relatos emocionales como argumentos. Aunque denuncian la inseguridad y el miedo como arma de manipulación sobre las masas, lo cierto es que la propuesta hace lo mismo con el miedo al cambio climático y al aumento poblacional, argumentos de sobra inducidos por la ONU y sus agencias, en lo que se ha denunciado como gobierno global.

Respecto a las emotividades utilizadas transversalmente (sentimientos, recuerdos, sensaciones) para fijar metas, no dejan de percibirse como promesas demagógicas de paraísos emocionales (el centro histórico como una suerte de safe space). Lo anterior no se fundamenta racionalmente sino en pulsaciones sentimentales. Como los sentimientos son subjetivos y cualitativos, difícil de poderse medir o verificar, por lo que improbable de cumplir como meta. Nancy Fraser nos recuerda en su obra ¿Qué es la justicia social? Reconocimiento y distribución (Fraser, 2005), que una percepción no siempre está relacionada con el individuo y la satisfacción de sus necesidades, sino con la comunidad y el reconocimiento de su existencia. Musset también conviene que nuestros marcos metodológicos y de interpretación pueden ser cuestionados pues la ciudad justa es una percepción compleja definida por vivencias colectivas en el tiempo y espacio determinado (2015). Ello no impide, continúa el autor, que:

hasta los más miserables adopten el discurso dominante para explicar y legitimar su pobreza, poniéndose en una situación de alienación. Ellos aceptan las desigualdades más descaradas porque las consideran normales (y justas) en un mundo dividido por naturaleza o irremediable fatalismo entre ricos y pobres.

El mayor problema de proponer una ciudad justa radica, en que si bien se pueden medir las desigualdades (acceso a servicios públicos, desarrollo humano, empleo, salarios, etc.) no pasa lo mismo con las injusticias, condicionadas por la percepción que modelan los contextos históricos, culturales, sociales de individuos y colectivos. Este cálculo es imposible y depende más del campo de la psicología social que de la economía cuantitativa (Musset, 2015).

Las acciones propuestas sólo implicaron de manera superficial a las comunidades afectadas, por lo que ni la continuidad ni el impacto son esperables. En sus planteamientos teóricos, el PM tiene razones en identificar bien elementos claves para la revitalización del $\mathrm{CHDC}$, como la inclusión y la justicia social. Pero no le corresponde 
ni a la herramienta ni a sus emisores, en este caso universitarios españoles, plantearlo, menos liderarlo. Esto último corresponde a las organizaciones locales, de carácter público, privado, barriales, gremiales, académicas, sociales y más que se sitúan en esta parte de la ciudad.

\section{Conclusiones}

Encontramos en la concepción y objetivos del Plan Maestro del Centro Histórico de la capital de Honduras el uso de metáforas urbanas como estrategia de persuasión del urbanismo planetario. En esa persuasión, se hizo uso de las adjetivaciones urbanas más reiteradas en los años recientes, como el de ciudad afectiva y urbanismo táctico. Tras esa cubierta, se encontraron procedimientos impropios de sistemas eficientes y transparentes, como la adjudicación directa del proyecto a consultores extranjeros para los productos más importantes, nacionales para los complementarios.

Otra metáfora muy divulgada en la campaña publicitaria montada fue la de la participación ciudadana. Esta no llegó a ser ni remotamente representativa de los millón y medio de capitalinos, pero una serie de eslóganes y afiches ratifican a los ciudadanos que todo fue hecho con el mejor consenso posible. Entre las instituciones públicas involucradas se pudo ver que tuvieron un rol secundario, además de haber excluido a sectores importantes de la reflexión teórica, como el Instituto de Geografía e Historia, la carrera de Historia y postgrados de Ciencias Sociales de la UNAH e investigadores urbanos confirmados. También excluyeron de la propuesta, a representantes la Dirección de Artes y Cultura, ello a pesar de identificar el Paisaje Urbano Histórico como pieza clave para generar autoestima ciudadana. Tampoco se invitó a la Cámara de Comercio de Tegucigalpa y sectores más amplios y afianzados de la población, como patronatos, parroquias y otros. Esta omisión favoreció la reducción de voces críticas a los planteamientos urbanos, como el de urbanismo táctico y emotivos. De igual manera favorece la incorporación de soluciones urbanas como un teleférico para Tegucigalpa, emulando el de Medellín. De manera que el PMCH se vuelve en un buen pretexto para contratar consultores y comprar equipamientos urbanos, móviles para la restringida participación, que a lo sumo podrá llevarse unas pocas intervenciones a carácter "hágalo usted mismo" en el maltrecho centro histórico. El elemento clave y ausente en estas iniciativas sigue siendo el de la transparencia, enemiga natural de la colusión, imposición y corrupción. Y las metáforas urbanas son el lenguaje bien intencionado perfecto para la legitimación de tales actuaciones.

\section{Referencias bibliográficas}

Bourdieu, P., y Wacquant, L. (2001). Las astucias de la razón imperialista. España: Paidós Asterisco.

Casanova, H., y Hernández, J. (Eds.) (2015). Public space acupuncture. New York: Actar.

Davis, M. (1995) Control urbano: la ecología del miedo. Barcelona: Virus.

Lefebvre, H. (1968). Le Droit à la ville. Paris : Anthropos.

Lefebvre, H. (1970). La révolution urbaine. Paris : Gallimard.

Lerner, J. (2014). Urban Acupuncture. Washington : Island Press.

Pradilla, E., y Sodi, D. (2006). La ciudad incluyente. Un proyecto democrático para el Distrito Federal opción izquierda Metropolitana A.C.-OIDME. México: Océano.

Rawls, J. (2008). La justicia como equidad (Justice as fairness). España: Paidós.

Webber, M. (2004). La era postciudad, en Ángel Martín Ramos (ed.). Lo urbano en 20 autores contemporáneos. Barcelona: UPC, 13-23. 


\section{Periódicos}

El Heraldo. (2018, 17 de noviembre). Hoy arranca el primer Festival Naranja de la capital de Honduras. El Heraldo, Honduras. https://www.latribuna.hn/2019/11/21/ hoy-arranca-el-festival-naranja-en-tegucigalpa/

Lefebvre, H. (1989, mayo). Quand la ville se perd dans une métamorphose planétaire. Le Monde diplomatique.

León Noticias. (2017, 24 de abril). El arquitecto leonés Javier Ramos Guallart, Premio Sandoval 2017 del Ayuntamiento de Mansilla Mayor. León Noticias. https://www.leonoticias.com/comarcas/201704/24/arquitecto-leones-javierramos-20170424143154.html

Suárez, A (2017, 8 de septiembre) El centro histórico era invisible hace 10 años. El Heraldo, Honduras. https://www.elheraldo.hn/revistas/tic-tac/1106473-466/ arturo-su\%C3\%A1rez-lobo-el-centro-hist\%C3\%B3rico-era-invisible-hace-10$\mathrm{a} \% \mathrm{C} 3 \% \mathrm{~B} 10 \mathrm{~s}$

\section{Revistas}

Brenner, N. (2013) Thesis on urbanization. Public Culture 251 (69). 85-114.

Crouch, D. (1998). Domesticating the street: the contested spaces of the high street and the mall. En N. Fyfe (Ed.), Images of the street: Planning, Identity, and control in public space, 176-191.

Delgadillo, V. (2016, septiembre-diciembre). "Financiarización y mercantilización del desarrollo urbano en escala planetaria. Entrevista a Carlos A. de Mattos". Revista Andamios 13 (32), 213-243.

Delgadillo, V. (2019, julio-diciembre) "Metáforas de las ciudades latinoamericanas ¿conceptos y adjetivaciones importadas, neutras y despolitizadas?" Revistarquis 8 (2), 49-65.

Galvis, J. (2019). Del higienismo a la acupuntura urbana. Metáforas médicas y urbanismo excluyente en Bogotá. Revista Territorios 42, 3-24.

Lefebvre, Henri (2004 [1989]). "Quand la ville se perd dans une métamorphose planétaire", Paris, La Somme et le Reste, Etudes lefebvriennes. Reseau mundial, (3), 21-23.

Musset, A. (2015). El mito de la ciudad justa. Una estafa neoliberal. Revista Bitácora Urbano Territorial, 25(1),125-134. https://www.redalyc.org/articulo. oa? id=748/74841604002

Navarrete, D. (2008). "Tegucigalpa espejismo de la modernidad: el impacto de los discursos liberal y neoliberal sobre la capital de Honduras (siglos XIX y XX)". Les Cahiers Amérique latine Histoire et mémoire. 8(15). https://journals.openedition. org/alhim/2918

Navarrete, D. (2018). "De Metroplan a la (De)construcción postmoderna de Tegucigalpa, Honduras, 1972-1994". Revista Estudios Sociales. https://play.google.com/books/ reader?id=iXxIDwAAQBAJ\&hl=es\&pg=GBS.PA70

Peck, J. (2005). Struggling with the Creative Class. International Journal of Urban \& Regional Research 29 (4), 740-770.

Ríos, C. (2016, julio-diciembre). Ciudades de conductas esperadas: el derecho a la ciudad y el espacio público como mecanismo de control social. Vínculos. (9), 131142.

Shatkin, G. (2011). Coping with actually existing urbanisms: The real politics of planning in the global era. Planning Theory 10(1), 79-87. 


\section{Ponencias en congresos}

Bisquert, A. (1997). El urbanismo de los afectos. Infancia urbana y vida cotidiana actas de las Jornadas "Ios niños en la ciudad": Madrid.

Dos Santos, L. et alt. (2018). "Empresariamento urbano e as políticas relativas ao planejamento urbano estratégico da cidade de Belo Horizonte, Minas.

Gerais". En ICA 56 "Ciudades latinoamericanas: continuidades y cambios; tensión e interacción en la globalización". Universidad de Salamanca, España.

Valverde, F., y Alvarez, A., (2018) "La Regeneración Urbana como estrategia de dominación de clase. Las conexiones europeo-americanas a debate". En ICA 56 "Ciudades latinoamericanas: continuidades y cambios; tensión e interacción en la globalización". Universidad de Salamanca, España.

\section{Documentos}

AECID. (2016). Ciclo de gestión de Centros Históricos-Buenas prácticas: mejoramiento de viviendas en el Paseo de Ronda de La Alameda, Comayagua. Uso de especies botánicas nativas. http://www.aecid.hn/sitio/index.php/publicaciones-interes/ patrimonio-y-cultura/163-ciclo-gestion-centros-historicos-informes

AECID. (2016). Programa Comayagua Colonial Estudio de Impacto y Monitoreo de la Revitalización del Centro Histórico. http://www.aecid.hn/sitio/index.php/ publicaciones-interes/patrimonio-y-cultura/171-comayagua-colonial-impactomonitoreo-centro-historico

AMDC. (2019). Portal de la Alcaldía Municipal del Distrito Central. Gerencia del Centro Histórico. https://www.amdc.hn/index.php/amdc/gerencias-amdc/381-gerenciadel-centro-historico

Garcia, A. (2017-2918). Paisaje urbano histórico. Aplicación de la Recomendación en el Centro histórico del Distrito Central de Honduras. Tesis de master en arquitectura y patrimonio histórico. Universidad de Sevilla.

González, R. (sin fecha). Planes maestros como herramienta de gestión de Megaproyectos de Diseño Urbano liderados por el Estado y ejecutados por el sector privado: el caso del Portal Bicentenario Cerrillos. pp. 66

Ramos, J. (2011). Informe sobre el centro histórico de Tegucigalpa (Honduras) y las necesidades que puede cubrir la cooperación española. Madrid http://webcache. googleusercontent.com/search?q=cache:67VdWwZmJIYJ:aula.aguapedia.org/ pluginfile.php/16901/mod_folder/content/0/

Naciones Unidas (2017). Nueva agenda urbana. Quito: Hábitat III.

Sitios web

AECID. (2018) Presentación Pública del Plan Maestro del Centro Histórico de Tegucigalpa. http://www.aecid.hn/sitio/index.php/noticias/385-planmaestrotegucigalpa

Facebook de Plan Maestro Centro Histórico. https://es-la.facebook.com/ PlanMaestrodelCentroHistorico/?ref=page_internal

\section{CD-ROM}

PMCH. (2018). Plan Maestro del Centro Histórico del Distrito Central. Documento provisional. [CD ROM]. Universidad de Sevilla/AECID. 